\title{
Análise do manganês em solos de áreas ciliares do Parque Estadual do Rio Doce após o rompimento da barragem de Fundão em Mariana/MG
}

\author{
Analysis of manganese in soils in riparian areas of the Rio Doce State Park after the Fundão dam
}

rupture in Mariana/MG

Análisis de manganeso en suelos en áreas ribereñas del Parque Estatal Rio Doce luego de la ruptura de la presa Fundão en Mariana/MG

Recebido: 06/01/2021 | Revisado: 14/01/2021 | Aceito: 16/01/2021 | Publicado: 20/01/2021

Clara Diniz Oliveira Vasconcellos

ORCID: https://orcid.org/0000-0001-9353-5351 Universidade Federal dos Vales do Jequitinhonha e Mucuri, Brasil

E-mail: claradiniz92@yahoo.com.br

Alexandre Sylvio Vieira da Costa

ORCID: https://orcid.org/0000-0001-7251-7816

Universidade Federal dos Vales do Jequitinhonha e Mucuri, Brasil E-mail: alexandre.costa@ufvjm.edu.br

Jairo Lisboa Rodrigues

ORCID: https://orcid.org/0000-0001-6088-5232

Universidade Federal dos Vales do Jequitinhonha e Mucuri, Brasil E-mail: jairo.rodrigues@ufvjm.edu.br

Renata Soares Farias Campos

ORCID: https://orcid.org/0000-0002-2046-3235 Universidade Vale do Rio Doce, Brasil E-mail: renatacampos@ hotmail.com.br

Mayra Soares Santos

ORCID: https://orcid.org/0000-0003-4314-7507 Universidade Federal dos Vales do Jequitinhonha e Mucuri, Brasil E-mail: mayra.4684@hotmail.com.br

Rodrigo de Carvalho Hott

ORCID: https://orcid.org/0000-0002-4042-4364 Universidade Federal dos Vales do Jequitinhonha e Mucuri, Brasil E-mail: rrodhott@yahoo.edu.br

Wady Dutra Neto

ORCID: https://orcid.org/0000-0001-9897-3465 Universidade Vale do Rio Doce, Brasil

E-mail: wadyneto@outlook.com

\begin{abstract}
Resumo
A importância econômica da atividade mineradora bem como a sua demanda mundial, causam impactos socioambientais desde o processo de implementação da atividade até a disposição final dos rejeitos. O rompimento da barragem de Fundão, localizada em Mariana-MG, que armazenava os rejeitos do beneficiamento de minério de ferro promoveu inestímaveis prejuízos ambientais na bacia do rio Doce. O presente trabalho teve como objetivo identificar os níveis de manganês nos solos das áreas ciliares no Parque Estadual do Rio Doce após o rompimento da barragem de rejeito de Fundão. Foram analisadas seis áreas dos rios Doce, Mombaça e Turvo sendo três afetadas diretamente pelo rejeito e três não afetadas. $\mathrm{O}$ modelo experimental utilizado foi um fatorial $3 \times 2 \times 2$ : três rios, dois pontos (montante e jusante), e dois anos de coleta (2016 e 2017) com quatro repetições. Os resultados mostraram que os níveis médios de manganês foram mais elevados na área ciliar do rio Mombaça em comparação ao rio Doce, mesmo apresentando apenas uma das suas áreas afetada pelos rejeitos. Entre 2016 e 2017 foi observado uma tendência de redução dos valores de manganês. Das áreas afetadas, o trecho a jusante do rio Mombaça apresentou valores mais elevados quando comparado as áreas ciliares analisadas e afetadas pelos rejeitos no rio Doce. As áreas do rio Turvo, não atingido pelos rejeitos, apresentaram os menores valores de concentração de manganês. Os resultados indicam acréscimo na concentração de manganês nos solos das áreas ciliares dos rios afetados mas de forma diferenciada.
\end{abstract}

Palavras-chave: Mineração; Barragem; Rejeito; Metais; Contaminação.

\section{Abstract}

The economic importance of mining activity, as well as its worldwide demand, cause socio-environmental impacts from the process of implementing the activity to the final disposal of the tailings. The rupture of the Fundão dam, located in Mariana-MG, which stored the waste from the processing of iron ore, promoted invaluable environmental 
damage in the Doce river basin. The present work had as objective to identify the levels of manganese in the soils of the riparian areas in the Doce river State Park after the rupture of the Fundão tailings dam. Six areas of the Doce, Mombaça and Turvo rivers were analyzed, three of which were directly affected by the tailings and three were not affected. The experimental model used was a $3 \times 2 \times 2$ factorial: three rivers, two points (upstream and downstream), and two years of collection (2016 and 2017) with four replications. The results showed that the average levels of manganese were higher in the riparian area of the Mombasa river compared to the Doce river, even with only one of its areas affected by the tailings. Between 2016 and 2017, there was a downward trend in manganese values. Of the affected areas, the stretch downstream of the Mombasa river showed higher values when compared to the riparian areas analyzed and affected by the tailings in the Doce river. The areas of the Turvo river, not reached by the tailings, presented the lowest values of manganese concentration. The results indicate an increase in the concentration of manganese in the soils of the riparian areas of the affected rivers, but in a different way.

Keywords: Mining; Dam; Reject; Metals; Contamination.

\section{Resumen}

La importancia económica de la actividad minera, así como su demanda mundial, provocan impactos socioambientales desde el proceso de implementación de la actividad hasta la disposición final de los relaves. La interrupción de la represa Fundão, ubicada en Mariana-MG, que almacenaba los desechos del procesamiento del mineral de hierro, promovió un invaluable daño ambiental en la cuenca del río Doce. El presente trabajo tuvo como objetivo identificar los niveles de manganeso en los suelos de las áreas ribereñas del Parque Estatal Rio Doce luego de la ruptura del tranque de relaves Fundão. Se analizaron seis áreas de los ríos Doce, Mombaça y Turvo, tres de las cuales fueron afectadas directamente por los relaves y tres no fueron afectadas. El modelo experimental utilizado fue un factorial $3 \times 2 \times 2$ : tres ríos, dos puntos (río arriba y río abajo) y dos años de recolección (2016 y 2017) con cuatro repeticiones. Los resultados mostraron que los niveles promedio de manganeso fueron más altos en el área ribereña del río Mombasa en comparación con el río Doce, incluso con solo una de sus áreas afectada por los relaves. Entre 2016 y 2017, hubo una tendencia a la baja en los valores de manganeso. De las áreas afectadas, el tramo aguas abajo del río Mombasa mostró valores más altos en comparación con las áreas ribereñas analizadas y afectadas por los relaves en el río Doce. Las áreas del río Turvo, no alcanzadas por los relaves, presentaron los valores más bajos de concentración de manganeso. Los resultados indican un aumento de la concentración de manganeso en los suelos de las zonas ribereñas de los ríos afectados, pero de forma diferente.

Palabras clave: Minería; Represa; Rechazar; Rieles; Contaminación.

\section{Introdução}

A atividade mineradora fornece a sociedade um elevado número de matérias-primas e insumos, essenciais ao conforto, manutenção da vida e ao progresso da civilização. A sua relevância social está presente em diversos setores como na agricultura, no qual substâncias minerais são utilizadas como fertilizantes; no setor da construção civil, medicina, transportes, ciência e tecnologia, bens de consumo e até mesmo no setor de comunicações (Tanno \& Sintoni, 2003).

O elemento ferro é o mais explorado na lista de exportações em território brasileiro, sendo responsável por aproximadamente $64 \%$ da renda gerada pela exportação de minérios no país (DNPM, 2017). O aumento na produção de minério de ferro promove grandes interações entre a atividade de extração e o meio ambiente. Esta interação pode gerar ônus a sociedade, ambiente e a economia, devido aos diversos impactos relacionados (Kopezinski, 2000). O grande volume de resíduos gerados na extração do minério de ferro é um aspecto ambiental relevante, uma vez que estes são em sua maioria depositados em barragens de contenção. Tal estrutura necessita de planejamento e controle adequado devido aos possíveis impactos relacionados (Ibram, 2016).

De acordo com a Revista do Ministério Público de Minas Gerais (2012) os impactos mais comuns da atividade de mineração são a alteração dos lençóis hídricos subterrâneos, poluição sonora, visual, da água superficial, ar e solo, impactos sobre a fauna, flora, ambientes aquáticos, cavernas, sítios históricos e arqueológicos e paleontológicos, bem como a indução de imigração e conflito pela terra.

No dia 5 de novembro de 2015, a barragem de Fundão localizada em Mariana-MG, que armazenava os rejeitos do tratamento de minério de ferro da empresa Samarco Mineração S.A rompeu. O evento foi classificado de acordo com o Governo do Estado de Minas Gerais como o maior desastre ambiental do Brasil e o maior do mundo envolvendo barragens de rejeito, afetando 35 cidades do estado de Minas Gerias e três do Espírito Santo. A barragem possuía 55 milhões de metros 
cúbicos de rejeito de minério. A lama percorreu $663 \mathrm{~km}$ ao longo dos rios Gualaxo do Norte, Carmo e Doce, promovendo inestimáveis prejuízos ambientais e socioeconômicos.

Os metais são introduzidos nos sistemas aquáticos e terrestres por meio da contribuição antrópica ou por fontes naturais através de processos geoquímicos, no processo de intemperismo (Yabe \& Oliveira, 1998).

As atividades industriais são responsáveis por gerarem poluição, muitas vezes em grandes volumes com reduzidos sistemas de controles ou mitigação das suas atividades ou como proporcionalidades muito dispares entre a poluição e sua mitigação. Considerando a fonte antrópica, poluentes como metais podem ser introduzidos nos ecossistemas por efluentes de diferentes tipos de indústrias, como mineradoras, galvanoplastia, curtumes e manufaturas de produtos eletrônicos (Lima \& Merçon, 2011).

O elemento manganês apresenta toxidade baixa e questionável quando ingerido. Existem poucos relatos de intoxicação por manganês via oral, porém há estudos relatando que crianças expostas por ingestão a níveis iguais ou superiores a $0,5 \mathrm{mg} \cdot \mathrm{L}^{-1} \mathrm{em}$ água potável apresentaram déficits intelectuais. A forma mais comum de intoxicação é por via inalatória, em minas, siderúrgicas e algumas indústrias químicas. Há estudos relatando distúrbios psiquiátricos graves em mineradores chilenos intoxicados por este metal (Giaia, 2016).

O Parque Estadual do Rio Doce (PERD) está inserido nos limites territoriais dos municípios de Timóteo (5\%), Dionísio (15\%) e Marliéria (80\%), no estado de Minas Gerais. Com superfície de 35.976,43 ha, foi criado pelo do decreto 1.119 de 14 de julho de 1994 sendo administrado atualmente pelo Instituto Estadual de Florestas (IEF) de Minas Gerais. O ecossistema local é caracterizado por Mata Atlântica - Floresta Estacional Semidecidual. No local são desenvolvidas atividades diversas como educação ambiental, recreação, monitoramento e controle florestal, coleta de sementes, produção de mudas, fomento florestal e pesquisa científica (IEF, 2019).

O objetivo deste trabalho foi identificar e quantificar os níveis de manganês nas áreas ciliares do Parque Estadual do Rio Doce após o rompimento da barragem de rejeito da Samarco em Mariana/MG, analisando pontos afetados diretamente pelo rejeito e pontos não afetados.

\section{Metodologia}

O projeto foi desenvolvido no laboratório de Química da Água e no Multiusuários da Universidade Federal dos Vales do Jequitinhonha e Mucuri (UFVJM), campus Teófilo Otoni -MG.

\subsection{Coleta das amostras de solo no Parque Estadual do Rio Doce}

Nos meses de março dos anos de 2016 e 2017, na região do Parque Estadual do Rio Doce (PERD), foram realizadas as coletas das amostras de solos na porção média da bacia do Rio Doce, em áreas ciliares de três rios, sendo esses o rio Doce, rio Mombaça e rio Turvo.

Nas áreas ciliares de cada curso d'água amostrado, foram delimitados dois pontos denominados de montante (M) e jusante (J) denominados rio Doce montante (RDM), rio Doce jusante (RDJ), rio Mombaça montante (RMM), rio Mombaça jusante (RMJ), rio Turvo montante (RTM) e rio turvo jusante (RTJ), totalizando seis pontos de coleta (Figura 1). O rio Mombaça a jusante teve contato direto com a pluma de rejeitos de mineração, bem como as áreas a montante e jusante localizadas nas margens do rio Doce. No rio Mombaça a montante e as duas áreas das margens do rio Turvo analisadas, não foram atingidas diretamente pelo rejeito.

Nas áreas a montante e a jusante foram demarcadas regiões, com aproximadamente 250 metros de comprimento. A região denominada "margem" indicada pela letra "E" se localiza a uma distância máxima de cinco metros das margens dos rios 
no período da coleta (Figura 2). Em cada um dos traçados, cinco pontos foram demarcados com aproximadamente 50 metros entre si, denominado amostra simples. Desta forma foram coletadas 30 amostras de solo em cada ano (2016 e 2017). As amostras foram retiradas na profundidade de $20 \mathrm{~cm}$ com trado holandês e com auxílio de uma espátula colocado em sacola plástica, vedada e identificada.

Figura 1 - Amostragem das áreas em estudo localizadas no PERD.

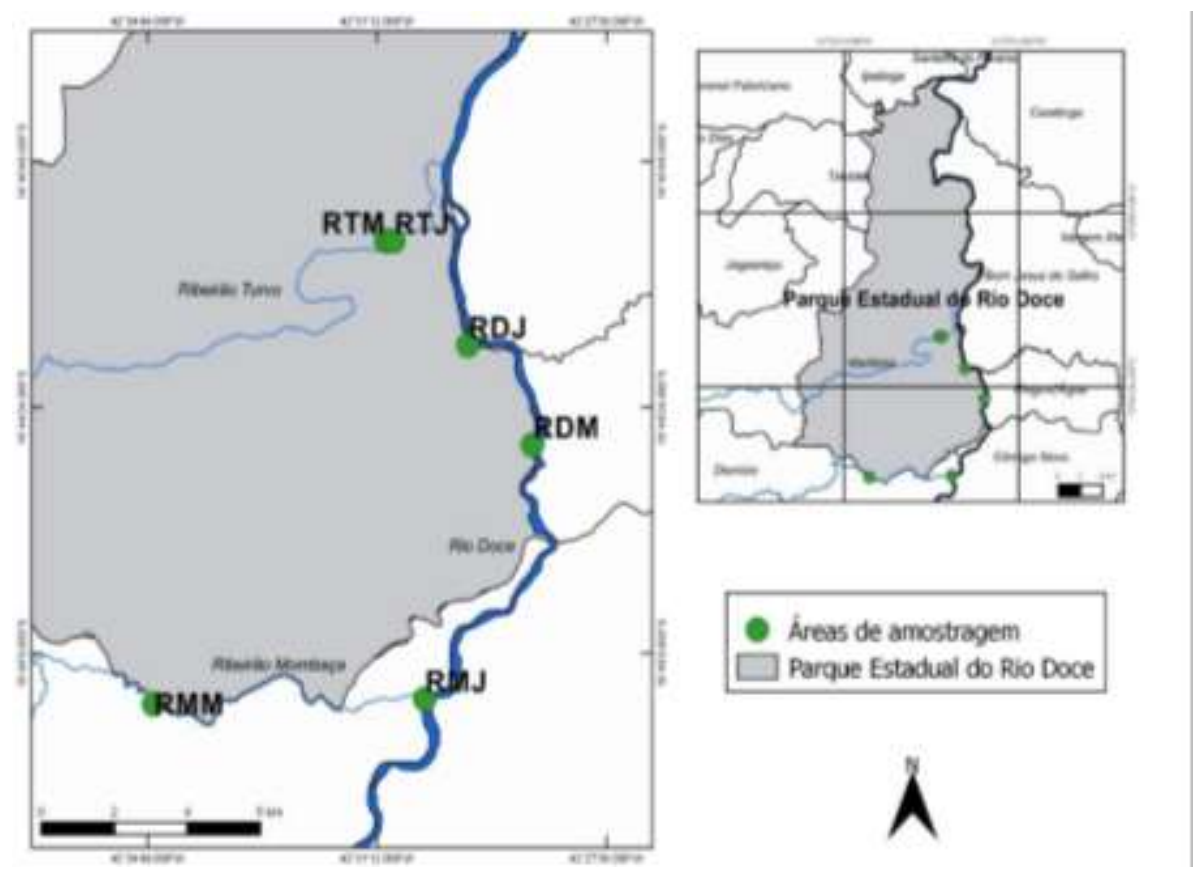

Fonte: Grupo de pesquisa da Universidade Vale do Rio Doce (2018).

A Figura 2 indica os pontos de coletas das amostras de solo que margeiam o PERD ao longo do Rio Doce. A coleta ocorreu na margem esquerda do rio. No ponto localizado a montante do rio Doce (RDM) observou-se maior deposição de rejeito sendo classificado como área altamente impactada e na área à jusante (RDJ) o rejeito foi depositado somente em alguns pontos ao longo do traçado escolhido, calssificado como área pouco impactada.

Figura 2 - Pontos de coleta das amostras de solo localizadas a margem do Rio Doce no PERD.
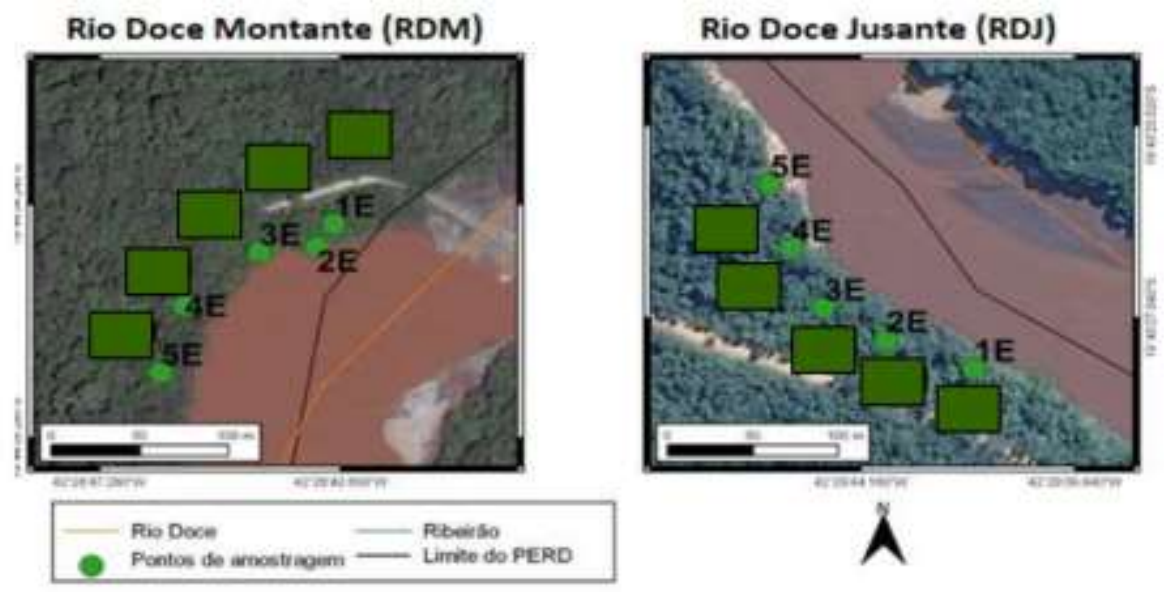

Fonte: Adaptado de grupo de pesquisa da Universidade Vale do Rio Doce, 2019. 
Na zona de amortecimento do PERD está localizado o terceiro ponto afetado diretamente pelo rejeito, situado especificamente a margem esquerda do Rio Mombaça, que deságua na margem esquerda do Rio Doce. Neste ponto localizado a jusante, as margens do Mombaça (RMJ) observou-se deposição moderada de rejeito, denominada área moderadamente afetada, entretando no ponto a montante do referido rio (RMM), não houve contato com o rejeito. Na Figura 3 observa-se a disposição dos pontos de amostragem no Rio Mombaça.

Figura 3 - Pontos de coleta das amostras de solo localizadas a margem do Ribeirão Mombaça no PERD e em sua zona de amortecimento.

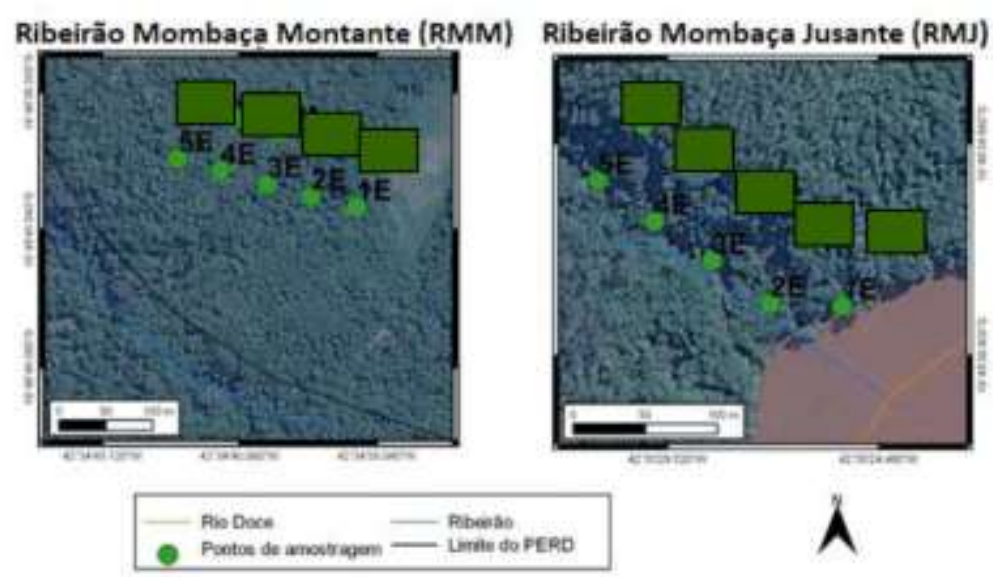

Fonte: Adaptado de grupo de pesquisa da Universidade Vale do Rio Doce (2019).

As amostras de solos referentes ao Rio Turvo, que também desagua na margem esquerda do Rio Doce, foram coletadas na margem direita do curso d'água que se localiza em uma região mais íngreme. As regiões das duas áreas de estudo, a montante (RTM) e a jusante (RTJ), se localizam mais próximas umas das outras comparado as áreas dos demais cursos d'água, conforme se observa na Figura 4. Estas áreas não foram atingidas pelos rejeitos provenientes da barragem de Fundão.

Devido aos diferentes níveis de impacto dos rejeitos nas margens dos rios analisados, foi criado uma classificação em relação a quantidade de rejeito presente na área. Desta forma, a área rio Doce montante (RDM) foi classificada como "área muito impactada pelo rejeito"; rio Mombaça jusante (RMJ) como "área moderadamente impactada pelo rejeito" e rio Doce jusante (RDJ) como "área pouco impactada pelo rejeito".

Figura 4 - Pontos de coleta das amostras de solo localizadas a margem do Rio Turvo no PERD.

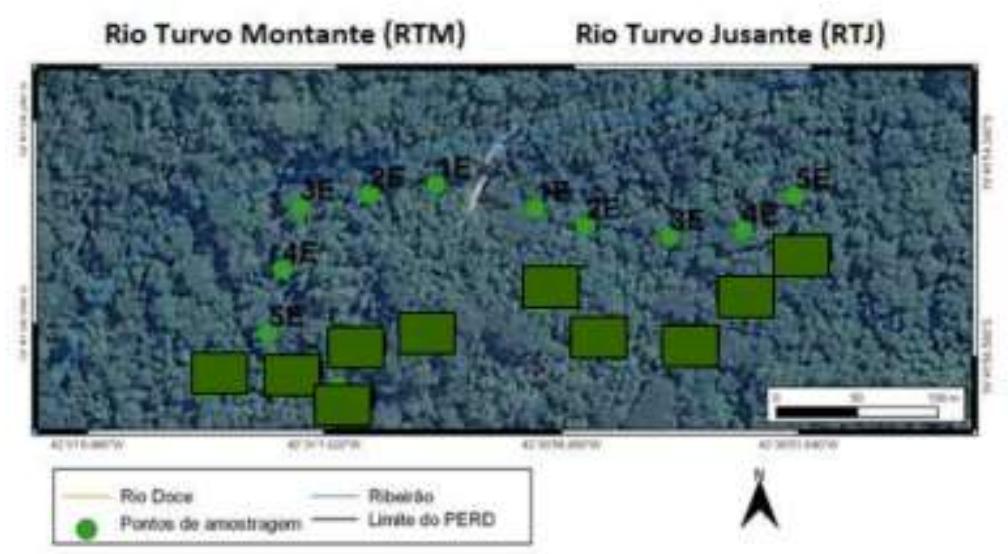

Fonte: Adaptado de grupo de pesquisa da Universidade Vale do Rio Doce (2019). 
As amostras de solos coletadas foram levadas ao laboratório de solos da Universidade Vale do Rio Doce e secadas a sombra, destorroadas e peneiradas (peneiras malha 2,0mm) para uniformização de suas partículas.

\subsection{Preparação e análise das amostras}

As amostras foram encaminhadas ao laboratório de Química da Água e Laboratório Multiusuários da Universidade Federal do Vale do Jequitinhonha (UFVJM) - Campus Mucuri, para determinação do manganês através de espectrometria de massas com plasma indutivamente acoplado (ICP-MS). De acordo com Hott (2016), esta técnica é eficaz para determinação de múltiplos elementos, ideal para análise de solo.

No processo de preparação das amostras para análise realizou-se o processo de digestão ácida conforme método USEPA 3051ª , por micro-ondas MARS-6® (910900, CEM, U.SA). As 60 amostras foram digeridas conforme procedimento metodológico já descrito. De acordo com Caires (2009), os métodos USEPA são considerados de alta tecnologia devido a utilização da radiação de micro-ondas em sua execução.

As amostras digeridas foram transferidas para um microtubo tipo Eppendorf $2 \mathrm{ml}$ para conservação até o processo de diluição e posterior análise no ICP-MS. Em seguida foram inseridas no equipamento para leitura da concentração de manganês conforme grau de contato com o rejeito proveniente do rompimento da barragem. Sendo assim as primeiras amostras foram as do rio Turvo a montante e jusante (não afetadas pelos rejeitos), após as do rio Mombaça a montante (não afetada pelos rejeitos), rio Doce a jusante (pouco afetada pelos rejeitos), seguido pelo rio Mombaça a jusante (moderadamente afetada pelos rejeitos) e então as amostras do rio Doce a montante (muito afetada pelos rejeitos), a fim de evitar que as amostras com uma possível alta concentração de contaminantes passasse no equipamento antes das amostras com menor potencial, causando interferências no equipamento.

Após a obtenção dos dados, os valores foram tabulados em Excel e analisados no programa EstatJab. Em seguida foram descartados um dos resultados obtidos de cada local de coleta considerando o que mais variava em relação aos demais valores obtidos. $\mathrm{O}$ modelo experimental utilizado foi o fatorial $3 \times 2 \times 2$ com quatro repetições. O primeiro fator foram os rios (Doce, Mombaça e Turvo), o segundo fator seus locais (montante e jusante) e o terceiro fator os anos de coleta (2016 e 2017). Foi avaliado o elemento manganês presente nas áreas. O delineamento experimental utilizado foi o inteiramente casualizado. Na avaliação entre as médias foi utilizada a Anova com teste de Tukey a 5\% de probabilidade.

\section{Resultados e Discussão}

Dentre os diversos minerais presentes ao longo do Rio Doce depositados pelos rejeitos da Mineradora Samarco e/ou por outros processos, identificamos o manganês. Este elemento é comumente encontrado no minério de ferro associado aos óxido-compostos (Pirolusita, Manganita e Hausmanita), sulfetos, carbonatos e silicatos. É um dos principais metais encontrados nas rochas ígneas, sedimentares e metamórficas (Martins, 2003).

Observa-se no Gráfico 1 que as maiores concentrações de manganês foram identificadas as margens do rio Mombaça, que apresentou apenas uma de suas áreas de coleta atingida pelos rejeitos, seguido pelos solos das margens do rio Doce que apresentou os seus dois pontos de coleta, montante e jusante, atingidos pelos rejeitos, mas com intensidades distintas (muito impactado pelos rejeitos e pouco impactado pelos rejeitos).

Nas áreas ciliares do rio Turvo analisadas não ocorreu interferência dos rejeitos de mineração nos solos em nenhum dos pontos avaliados. Observa-se que neste rio os valores são reduzidos e estatisticamente inferiores aos valores obtidos nos solos as margens dos rios Doce e Mombaça. Os valores da concentração de manganês nas áreas ciliares rio Turvo foram de aproximadamente $57 \%$ e $80 \%$ inferiores aos valores da concentração de manganês das áreas ciliares dos rios Doce e Mombaça, respectivamente. 
Sabe-se que historicamente o rio Doce e seus afluentes nas regiões de algumas cabeceiras, são contaminados e impactados devido as atividades de mineração e o manganês é um dos elementos que compõem os rejeitos de mineração, em diferentes concentrações. Segundo Wolff (2009), o nível de manganês nos rejeitos da barragem rompida era de aproximadamente $1 \%$. Estudos referentes a qualidade da água indicaram que após o rompimento da barragem os valores deste elemento subiram de forma significativa, retornando a parâmetros normais aproximadamente cinco meses após o rompimento (Dias et al., 2018).

Gráfico 1 - Concentração de manganês nos solos das áreas ciliares dos rios avaliados no Parque Estadual do Rio Doce.

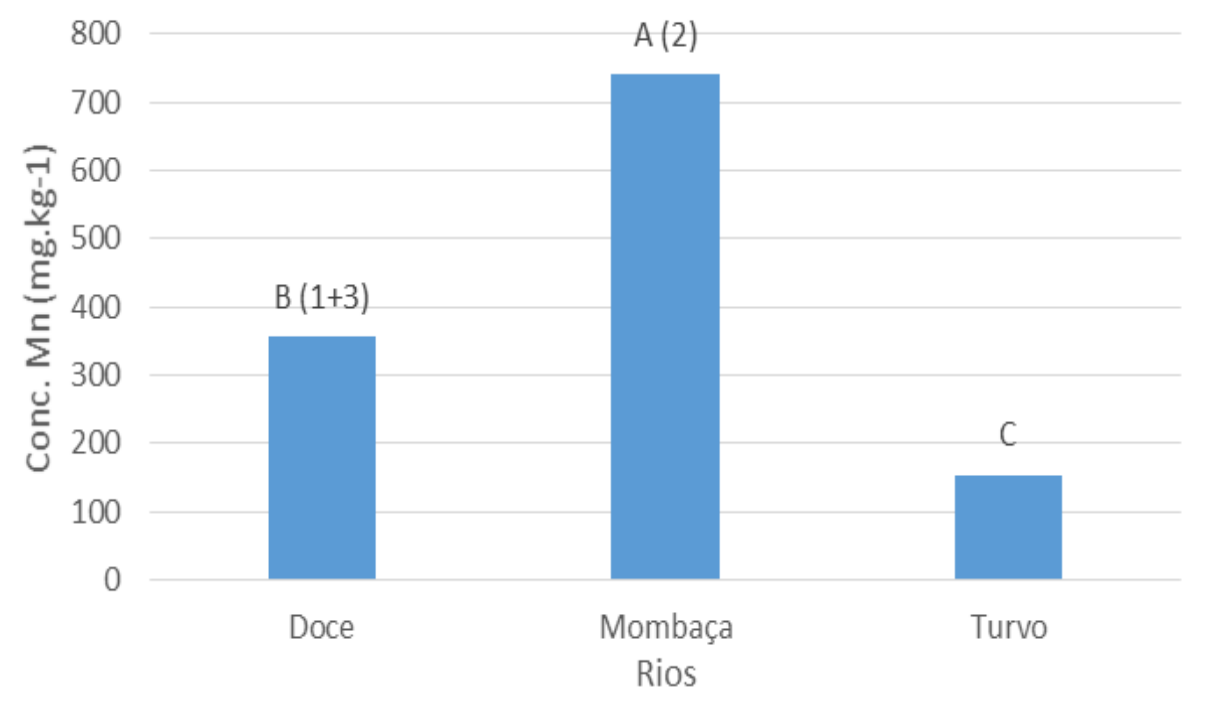

(1): Área muito impactada pelo rejeito. (2): Área moderadamente impactada pelo rejeito. (3): Área pouco impactada pelo rejeito.

Barras seguidas de mesma letra não diferem pelo teste de Tukey a $5 \%$ de probabilidade $(\mathrm{P}<0,05)$ Fonte: Autor (2020).

Dos solos coletados nos pontos a jusante e montante avaliados, duas áreas a jusante em um total de três, estavam pouco e moderadamente impactadas pelos rejeitos e a montante, do total de três áreas avaliadas, apenas uma área estava altamente impactada (Gráfico 2). Observa-se que na média das áreas avaliadas, a região a jusante apresentou valores mais elevados quando comparado a média das áreas a montante. A maior contribuição das áreas contaminadas nas regiões a jusante favoreceu ao aumento dos valores obtidos em relação as áreas a montante. 
Gráfico 2 - Concentração de manganês nos solos das áreas ciliares dos rios avaliados no Parque Estadual do Rio Doce em pontos a montante e a jusante.

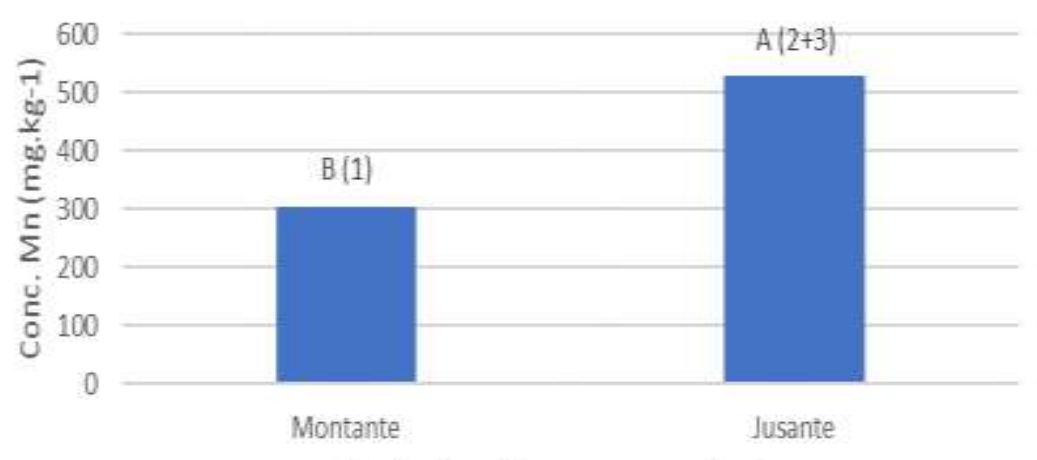

Pontos de coleta as margens dos rios

(1): Área muito impactada pelo rejeito.

(3): Área pouco impactada pelo rejeito

Barras seguidas de mesma letra não diferem pelo teste de Tukey a 5\% de probabilidade $(\mathrm{P}<0,05)$

Fonte: Autor (2020).

No Gráfico 3 verificamos os resultados obtidos para o elemento manganês considerando os anos de coleta das amostras de solo (2016 e 2017). Apesar de não serem observadas diferenças significativas, os valores médios das concentrações de manganês nos solos reduziram com o passar do tempo, de aproximadamente $450 \mathrm{mg} \cdot \mathrm{kg}^{-1} \mathrm{para} 375 \mathrm{mg} . \mathrm{kg}^{-1}$, uma redução de $17 \%$. Estes resultados podem ser parcialmente explicados considerando que, com a passagem de um período chuvoso entre os períodos de coleta, ocorreu o arraste de parte deste elemento novamente para os rios da região. Outra explicação está associada a fixação deste elemento nas partículas minerais e orgânicas do solo que, com o tempo, reduzem a sua disponibilidade no ambiente. Segundo Zhang et al. (2014), a biodisponibilidade de manganês nos solos depende de algumas de suas características como $\mathrm{pH}$, teor de matéria orgânica e potencial redox. Nos solos e sedimentos, o processo de oxidação do manganês está intimamente associado a atividade dos microrganismos (Martins, 2003).

Gráfico 3 - Concentração de manganês nas áreas ciliares das margens dos rios avaliados no Parque Estadual do Rio

Doce coletados em diferentes períodos (anos 2016 e 2017).

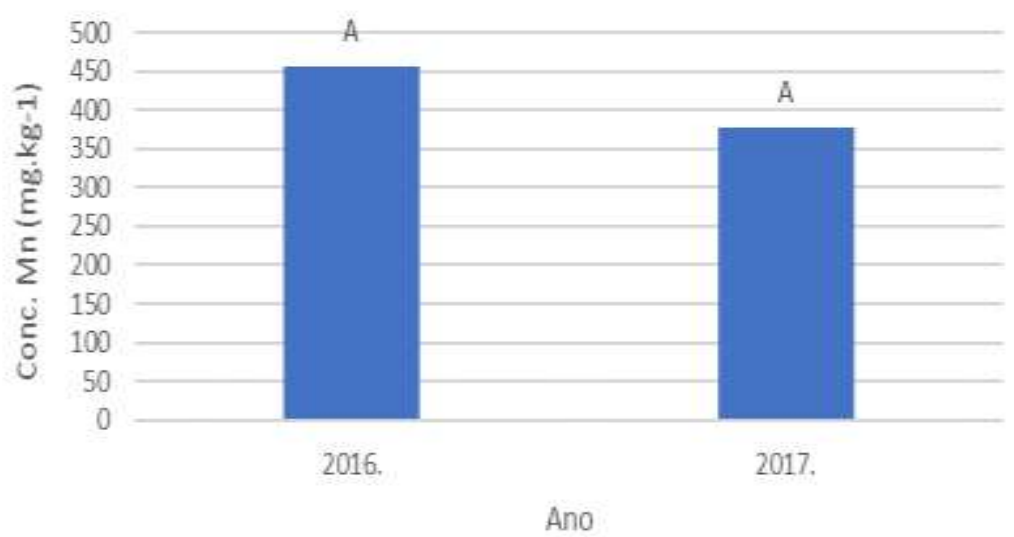

Barras seguidas de mesma letra não diferem pelo teste de Tukey a $5 \%$ de probabilidade $(\mathrm{P}<0,05)$ Fonte: Autor (2020). 
No Gráfico 4 verifica-se o nível de manganês em cada local onde foi realizada a coleta dos solos, a montante e a jusante. Nos dois pontos de coleta de solo as margens do rio Doce, a montante e jusante, verificamos que não foram observadas diferenças significativas, com valores variando entre 350 e $400 \mathrm{mg} \cdot \mathrm{kg}^{-1}$ de solo. Em ambos os pontos analisados os rejeitos de minério depositaram uma camada na superfície do solo em diferentes quantidades, gerando áreas que foram caracterizadas como de grande impacto dos rejeitos (1) e baixo impacto dos rejeitos (3). No rio Mombaça o setor jusante onde o solo foi classificado como moderadamente impactado pelos rejeitos da mineração (2), os valores de manganês do solo foram extremamente elevados, superiores a $1.100 \mathrm{mg} \cdot \mathrm{kg}^{-1}$ de solo. Nas áreas ciliares do mesmo rio, a montante, onde o solo não foi atingido pelos rejeitos da mineração, os valores ficaram em torno de $350 \mathrm{mg} \cdot \mathrm{kg}^{-1}$. Estes resultados indicam que, apesar da região classificada como jusante do rio Mombaça ser considerada visualmente uma região de médio impacto pelos rejeitos da mineração, em termos de contaminação por manganês foi o mais impactado. Como a área denominada jusante no rio Mombaça, está adentrando cerca de 50 metros distante do ponto de vazão no rio Doce, os resíduos de mineração chegaram em menor quantidade, mas de forma lenta e gradual, diferente das margens do rio Doce onde o fluxo dos rejeitos foi mais corrente. Esta lentidão do movimento pode ter favorecido a deposição mais intensa dos minerais de manganês que estavam em suspensão. Em relação aos pontos de coleta de solo nas áreas ciliares do rio Turvo, não atingido pelos rejeitos, os valores foram bem reduzidos, variando entre 190 e $140 \mathrm{mg} \cdot \mathrm{kg}^{-1}$ a montante e a jusante, respectivamente, não apresentando diferenças estatísticas significativas.

Gráfico 4 - Concentração de manganês nos solos das áreas ciliares dos rios avaliados na área do Parque estadual do Rio Doce nos pontos a montante e jusante de cada rio.

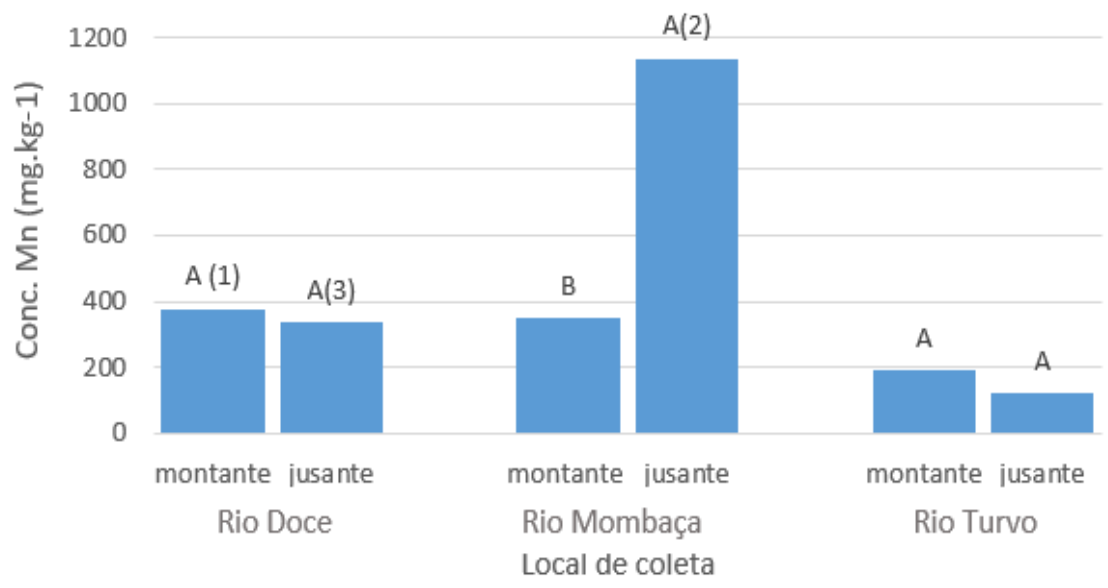

(1): Área muito impactada pelo rejeito

(2): Área moderadamente impactada pelo rejeito

(3): Área pouco impactada pelo rejeito

Barras seguidas de mesma letra não diferem pelo teste de Tukey a $5 \%$ de probabilidade $(\mathrm{P}<0,05)$

Fonte: Autor (2020).

Quando comparamos os resultados apresentados no Gráfico 5, nos pontos de coleta de solos classificados como montante, verificamos que os valores são estatisticamente iguais, apesar da área de coleta de solo denominada montante no rio Doce ser classificada como área de elevado impacto pelo rejeito e apresentar maior valor. A não existência de diferenças pode ser explicada considerando que, apesar de apresentar uma elevada quantidade de rejeitos depositadas no solo do local, a água corrente do rio Doce de maior fluxo e velocidade pode ter carreado grande parte deste manganês de volta para o rio Doce através do processo de lixiviação e arraste, mantendo os rejeitos de mineração mais densos depositados nestas áreas. Nos solos das áreas ciliares dos rios classificados como jusante, verificamos que as áreas do rio Doce e rio Mombaça foram impactadas 
de forma reduzida (3) e moderada (2), respectivamente, e a área do rio Turvo não impactada pelos rejeitos. Neste caso o rio Mombaça apresentou valores estatisticamente superiores as demais áreas ciliares dos rios, com valores de aproximadamente $1.150 \mathrm{mg} \cdot \mathrm{kg}^{-1}$, podendo ser explicado, provavelmente, pela maior deposição de elementos minerais em suspensão na água, já que é considerado uma área de médio impacto pelos rejeitos. Estes valores são considerados muito elevados por alguns

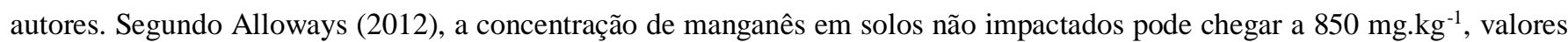
muito abaixo dos identificados nas áreas ciliares do rio Mombaça a jusante.

Gráfico 5 - Concentração de manganês nos solos das áreas ciliares dos rios avaliados na área do Parque Estadual do Rio Doce a montante e jusante.

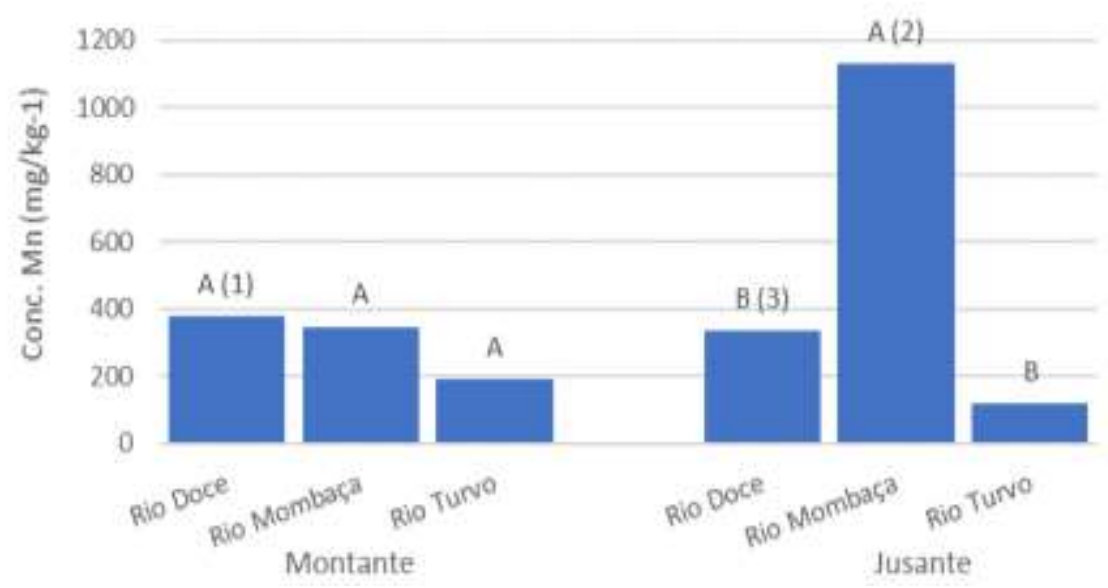

(1): Área muito impactada pelo rejeito.

(3): Área pouco impactada pelo rejeito

(2): Área moderadamente impactada pelo rejeito

Barras seguidas de mesma letra não diferem pelo teste de Tukey a $5 \%$ de probabilidade $(\mathrm{P}<0,05)$

Fonte: Autor (2020).

Constata-se no Gráfico 6 que não houve diferença estatística significativa nos pontos a montante e jusante entre os períodos avaliados (2016 e 2017), apesar de observarmos uma tendência de redução dos valores. Provavelmente entre 2016 e 2017 com a incidência de um período chuvoso entre as coletas, parte do manganês foi lixiviado para as camadas mais profundas do solo e carreados para o interior dos rios por arraste.

Gráfico 6 - Concentração de manganês nos solos das áreas ciliares dos rios avaliados na área do Parque Estadual do Rio Doce a montante e jusante nos períodos avaliados.

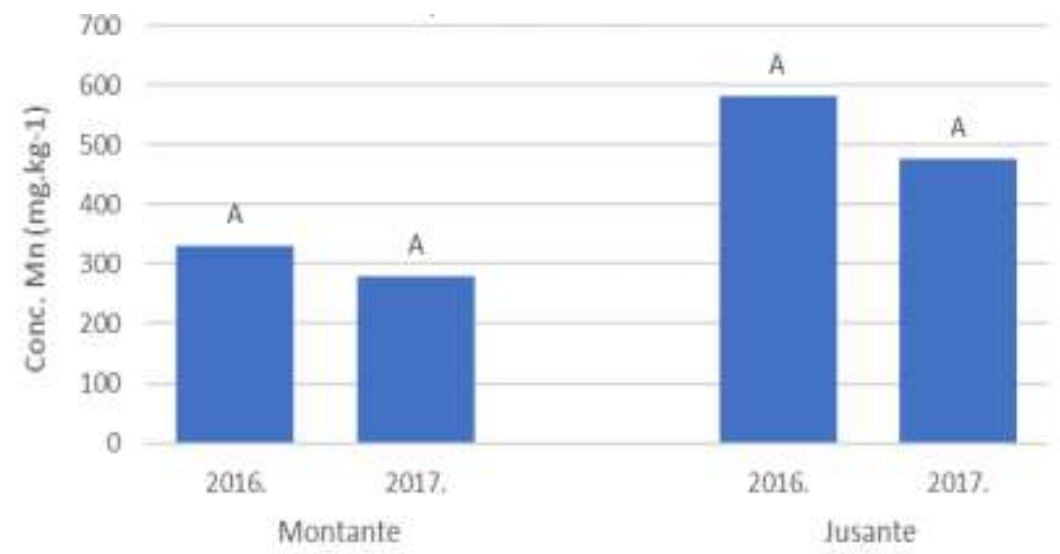

Barras seguidas de mesma letra não diferem pelo teste de Tukey a 5\% de probabilidade $(\mathrm{P}<0,05)$. Fonte: Autor $(2020)$. 
Quando comparamos os solos coletados nas margens de cada um dos rios nos dois anos de avaliação, verificamos a não existência de diferenças significativas entre eles (Gráfico 7), mas assim como foi observado no Gráfico 6, verificamos uma tendência de redução dos valores de concentração do manganês nos solos, comparando os anos de 2016 e 2017 , mesmo no rio Turvo que não teve suas margens afetadas pelos rejeitos.

Gráfico 7 - Concentração de manganês nos solos das áreas ciliares dos rios avaliados na área do Parque Estadual do Rio Doce nos períodos avaliados em cada rio.

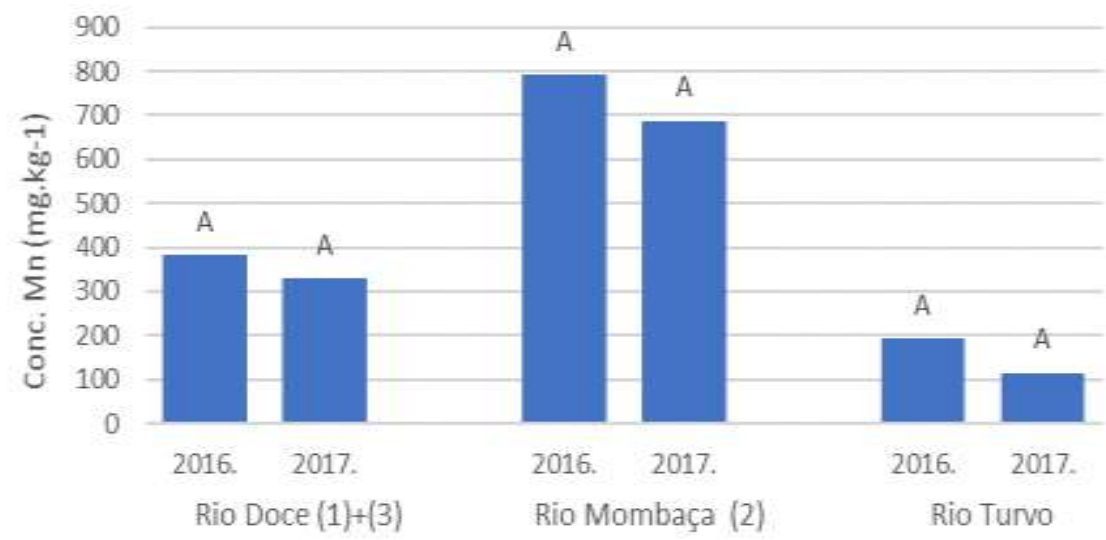

(1): Área muito impactada pelo rejeito. (2): Área moderadamente impactada pelo rejeito (3): Área pouco impactada pelo rejeito

Barras seguidas de mesma letra não diferem pelo teste de Tukey a $5 \%$ de probabilidade $(\mathrm{P}<0,05)$ Fonte: Autor (2020).

Na Tabela 1 verificamos a análise de interação dos diversos fatores avaliados. No rio Doce, tanto na área ciliar de coleta dos solos a montante quanto a jusante nos dois anos avaliados, não foram observadas quaisquer diferenças significativas, mesmo considerando que no setor montante tenha sido classificado como de elevado impacto pelos resíduos e no setor jusante de pouco impacto dos resíduos de mineração. No caso do rio Mombaça, destaque para o solo da área ciliar identificada como jusante e classificada como área moderadamente impactada onde os valores foram extremamente elevados nos dois anos de avaliação, quando comparado ao solo coletado no setor a montante, indicando um grande impacto dos resíduos da mineração neste local. Possivelmente o rejeito despejado pelo desastre supracitado interferiu na concentração do manganês das amostras de solo estudadas, assim como foi observado e analisado por Dutra (2018).

Segundo Paschke et al. (2005), o manganês é o $12^{\circ}$ elemento mais abundante na crosta terrestre, de ampla ocorrência natural e de intima ligação com as atividades industriais e minerárias. As atividades de mineração que envolvem manganês liberam no processo mais de 15\% deste elemento nos resíduos (Ge et al., 2004). Pesquisas desenvolvidas na região indicam que as atividades minerárias elevam significativamente as concentrações de manganês no solo e nos sedimentos da região. Estudos realizados por Leão et al. (2019) em águas e sedimentos da região do quadrilátero ferrífero em Minas Gerais observaram concentrações de manganês variando de 0,9 a 20.296 mg.L $\mathrm{L}^{-1}$, com valor médio de $1.770 \mathrm{mg} . \mathrm{L}^{-1}$, valor aproximadamente 17 vezes superior ao valor máximo permitido pela resolução Conama em relação a potabilidade, valores decorrentes de áreas de grandes minerações de ferro.

Outro grande problema ocorre na atividade microbiológica dos solos. Alguns autores citam que solos com elevados teores de metais pesados, incluindo o manganês, tem a sua diversidade biológica comprometida, assim como a dinâmica do processo de transformação da matéria orgânica e mineralização do nitrogênio (Rasted, 2010). Segundo Wei et al. (2014), os metais pesados nos solos em elevadas concentrações tornam-se um grande problema ambiental. 
Mas, apesar dos problemas causados pelo excesso deste elemento, alguns microrganismos se adaptam a condição, criando um novo equilíbrio. Abreu (2018) avaliou a tolerância das estirpes nativas de rizóbio de solos de áreas de mineração de manganês e sua associação com espécies leguminosas de feijão caupi (Vigna unguiculata) e Sabiá (Mimosa sp.). Verificou que, apesar do excesso de manganês no solo comprometer o desenvolvimento das plantas de feijão caupi, a simbiose não foi afetada, o mesmo ocorrendo com o sabiá.

Tabela 1 - Níveis de manganês dos solos $\left(\mathrm{mg} \mathrm{kg}^{-1}\right)$ coletados nas áreas ciliares dos rios avaliados na área do Parque Estadual do Rio Doce nos períodos avaliados.

\begin{tabular}{|c|c|c|c|c|}
\hline & \multicolumn{2}{|c|}{2016} & \multicolumn{2}{|c|}{2017} \\
\hline & Montante & Jusante & Montante & Jusante \\
\hline Rio Doce & $433,44^{(1)} \mathrm{Aa}$ & $332,24^{(3)} \mathrm{Ab}$ & $321,77^{(1)} \mathrm{Aa}$ & $337,71^{(3)} \mathrm{Ab}$ \\
\hline Rio Mombaça & $286,81 \mathrm{Ba}$ & $1295,74^{(2)} \mathrm{Aa}$ & $408,32 \mathrm{Ba}$ & $968,42^{(2)} \mathrm{Aa}$ \\
\hline Rio Turvo & $270,01 \mathrm{Aa}$ & $117,50 \mathrm{Ab}$ & $108,04 \mathrm{Aa}$ & $121,79 \mathrm{Ab}$ \\
\hline
\end{tabular}

-Médias seguidas das mesmas letras maiúsculas na linha não diferem pelo teste de Tukey a 5\% de probabilidade -Médias seguidas das mesmas letras minúsculas na coluna não diferem pelo teste de Tukey a $5 \%$ de probabilidade (1): Área muito impactada pelo rejeito. (2): Área moderadamente impactada pelo rejeito (3): Área pouco impactada pelo rejeito. Fonte: Autores (2020).

\section{Conclusão}

Os resultados obtidos neste artigo demonstram que as áreas ciliares atingidas pelos rejeitos da barragem de Mariana em Minas Gerais, apresentaram valores na concentração de manganês superior as áreas não atingidas. Apesar da área mais atingida pelos rejeitos se localizar nas margens do rio Doce, os maiores valores de manganês foram obtidos na área ciliar do rio Mombaça, menos atingido pelos rejeitos. Entre 2016 e 2017 verificou-se uma pequena queda nos valores de manganês nos solos que, apesar de não significativos, demostram a sua movimentação durante o período chuvoso. Os valores obtidos na região ciliar no ponto a jusante do rio Mombaça, superaram os $1.100 \mathrm{mg} \cdot \mathrm{kg}^{-1}$ de solo, valores excepcionalmente elevados.

\section{Referências}

Abreu, M. G. P. (2018). Tolerância e eficiência de rizóbios nativos de área de mineração de manganês no desenvolvimento de leguminosas. 68p. Dissertação (Mestrado), Universidade Federal do Ceará, Fortaleza.

Alloway, B. J. (2012). Heavy metals in soils: Trace metals and metalloids in soils and their bioavailability, V. 22, Springer Dordrecht Heidelberg New York London.

Caires, S. M. D. E. (2009). Determinação Dos Teores Naturais De Metais Pesados Em Solos do Estado de Minas Gerais como Subsídio ao Estabelecimento de valores de Referência de Qualidade. 270 p. Tese (Doutorado). Curso de Solos e Nutrição de Plantas, Universidade Federal de Viçosa.

Dias, C. A., Costa, A. S. V., Guedes, G. R., Umbelino, G. J. M., Sousa, L. G., Alves, J. H., \& Silva, T. G. M. (2018). Impactos do rompimento da barragem de Mariana na qualidade da água do rio Doce. Revista Espinhaço, 7(1):21-35.

DNPM-Departamento Nacional de Pesquisa Mineral (2017). Anuário Mineral Brasileiro: Principais substâncias metálicas. 28 p.

Dutra, P. R. F. (2018). Análise dos impactos relacionados ao rompimento da barragem de Fundão em Mariana/MG com ênfase em recursos hídricos. 52p. Tese (Doutorado). Curso de Gerenciamento de Recursos Hídricos, Universidade Federal de Minas Gerais, Belo Horizonte.

Giaia. Grupo Independente para Avaliação de Impacto Ambiental. (2016). Relatório Técnico: Determinação de metais na bacia do Rio Doce (Período: Dezembro -2015 a Abril-2016). 
Research, Society and Development, v. 10, n. 1, e39410111720, 2021 (CC BY 4.0) | ISSN 2525-3409 | DOI: http://dx.doi.org/10.33448/rsd-v10i1.11720

Ge, X. X., Cai, G. P., \& Zeng, G. M. (2004). Study on harmless disposal and comprehensive utilization of manganese sulfate waste residue. Chinas Manganese Ind. 22:11-14.

Hott, R. C. (2016). Adsorção e dessorção das espécies de arsênio (iii e v) e ácido monometilarsônico, pela k-jarosita, para proposta de remediação ambiental.77p. Dissertação (Mestrado). Programa de Pós-Graduação em Química, Universidade Federal dos Vales do Jequitinhonha e Mucuri, Teófilo Otoni.

IBRAM-Instituto Brasileiro de Mineração (Org.). (2016). Gestão e Manejo de Rejeitos da Mineração/Instituto Brasileiro de Mineração: Instituto Brasileiro de Mineração.128 p.

IEF-Instituto Estadual de Florestas (2019). Plano de Manejo do Parque Estadual do Rio Doce.

Kopezinski, I. (2000). Mineração X Meio Ambiente: considerações legais, principais impactos ambientais e seus processos modificadores: Editora Universidade. $103 \mathrm{p}$.

Leão, L. P., Costa, R. V. F., Leite, M. G. P., \& Junior, H. A. N. (2019). Mapeamento geoquímico do manganês e avaliação de qualidade de sedimentos fluviais e águas superficiais do quadrilátero ferrífero, Brasil. Anuário do instituto de Geociências, UFRJ, 42:444-455.

Lima, V. F., \& Merçon, F. (2011). Metais Pesados no Ensino de Química. Química Nova na Escola, 33(4):199-205.

Martins, I. (2003). Manganês. in: Azevedo, A. F., \& Chasin, A. A. M. Metais: gerenciamento da toxicidade. Editora Atheneu, v. I.

Ministério Público de Minas Gerais-Conselho Estadual de Política Ambiental (2011). Deliberação Normativa $n^{\circ} 166$, de 29 de junho de 2011 . Altera o Anexo I da Deliberação Normativa Conjunta COPAM CERH $n^{\circ} 2$ de 6 de setembro de 2010, estabelecendo os Valores de Referência de Qualidade dos Solos.

Paschke, M. W., Valdecantos, A. \& Redente, E. F. (2005). Manganese toxicity thresholds for restoration grass species. Environmental Pollution, 135:313-322.

Rashed, M. N. (2010). Monitoring of contaminated toxic and heavy metals from mine tailing through age accumulation in soil and some wild plants at Southeast Egypt. Journal Hazardous Materials, 178:739-746.

Tanno, L. C., \& Sintoni, A. (2003). Mineração \& município: bases para o planejamento de recursos naturais: Instituto de Pesquisas Tecnológicas (IPT).

Wei, Y., Hou, H., Shangguan, Y., Li, J., \& Li, F. (2014). Genetic diversity of endophytic bacteria of the manganese hyperaccumulating plant Phytolacca americana growing at a manganese mine. European Journal of Soil Biology, 62:15-21.

Wolff, A. P. (2009). Caracterização dos rejeitos de minério de ferro das minas da Vale. 107p. Dissertação (Mestrado). Curso de Pós-Graduação em Engenharia Mineral, Universidade Federal de Ouro Preto, Ouro Preto.

Yabe, M. J. S., \& Oliveira, E. (1998). Metais pesados em águas superficiais como estratégia de caracterização de bacias hidrográficas. Química Nova. 5(21):551-556.

Zhang, C., Yu, Z. G., Zeng, G. M., Jiang, M., Yang, Z. Z., Cui, F., Zhu, M. I., Shen, L. Q. \& Hu, L. (2014). Effects of sediment geochemical properties on heavy metal bioavailability. Environment International, 73:270-281. 